\title{
Navegando hacia Italia. El Reino de Cerdeña en el escenario político resultante de los tratados de Utrecht - Rastatt ${ }^{1}$
}

\author{
Lluís J. GUIA MARÍN ${ }^{2}$ \\ Universitat de València \\ 1luis.guia@uv.es
}

Fecha de recepción: 23/04/2013

Fecha de aceptación: 26/05/2013

\section{RESUMEN}

En 1713 finalizaba la administración de Carlos VI, ejercida desde Barcelona; por ello las disposiciones de gobierno, que habían llegado a la isla desde la capital catalana, dejaban de hacerlo. Con la institución en Viena, en 1714, del Consejo de España, los referentes territoriales y políticos del reino sardo serán sobre todo: Milán o Nápoles; con el espacio italiano ampliará sus lazos, sustituyendo aquellos que durante siglos había mantenido con los territorios ibéricos. Paralelamente Cerdeña pasaba a ser moneda de cambio en la búsqueda de un nuevo equilibrio territorial y político. La sombra imperial la mantuvo a salvo en Utrecht. Sin embargo la ruptura de ese equilibrio por parte de Felipe V, en 1717, precipitará lo que era una decisión anunciada: Cerdeña pasaba, en 1720, a los Saboya. Ello implicará su integración definitiva en el espacio italiano.

Palabras clave: Cerdeña, Italia, Utrecht, Carlos VI de Austria, Saboya.

\section{Sailing to Italy. The Kingdom of Sardinia in the political arena resulting from Treaties of Utrecht - Rastatt}

\begin{abstract}
In 1713 the administration of Charles VI, exerted from Barcelona, ended and thus also the provisions of government, which had reached Sardinia from the Catalan capital. With the institution in Vienna of the Council of Spain in 1714, the Sardinian kingdom territorial and political models were Milan or Naples. Sardinia expanded its ties with the Italian territories, replacing those kept with Spain for centuries. At the same, Sardinia became a bargaining chip in the search for a new territorial and political balance. The Imperial shade kept it safe in Utrecht. However, in 1717 Philip V broke this balance, thus precipitating a decision already known: in 1720 Sardinia passed to the House of Savoy. This will provoke its final integration into the Italian space.
\end{abstract}

Key words: Sardinia, Italy, Utrecht, Charles VI of Austria, Savoy.

$1 *$ El presente estudio se inscribe en el Proyecto de investigación "Rupturas y Pervivencias de la tradición jurídica y financiera de la Corona de Aragón en la crisis del Antiguo Régimen" (Ref. DER2012-37970 del Plan Nacional I+D), financiado por el Ministerio de Economía y Competitividad y por Fondos FEDER, España; y en la Commessa PC.P01.008.002, "Politiche difensive e sistemi di difesa degli Stati del Mediterraneo", del Consiglio Nazionale delle Ricerche, Italia.

2 ** Associato all'Istituto di Storia dell'Europa Mediterranea, Consiglio Nazionale delle Ricerche, Cagliari, Italia. 
Cuando en la primavera de 1713 la flota, que transportaba a Isabel Cristina y parte del austracismo hispánico hacia las costas italianas, soltaba amarras en el puerto de Barcelona, pocos podían imaginar, al menos en la isla, que el reino de Cerdeña también estaba cambiando definitivamente su destino. La administración ejercida por la emperatriz en nombre de su marido, Carlos de Habsburgo, desde la capital catalana había tocado a su fin ${ }^{3}$, y consecuentemente las disposiciones de gobierno, que pudiesen afectar al reino sardo y que regularmente habían llegado a la isla a través del Consejo de Aragón austracista, dejaban de hacerlo para seguir otros derroteros. Una de las primeras disposiciones cambiando el orden de las cosas se daba desde el puerto de Génova; en la ruta hacia Viena de la comitiva de la emperatriz, el marqués de Rialp se dirigía al regente de la Audiencia, Martín Vila, virrey interino, en estos términos:

...ha de procurar VS que las dependencias de gobierno, consultándolas y acordándolas en el Consejo, no recivan la menor suspensión,... y por lo militar se aurá de oir al General destinado a comandar essa gente de Guerra... Mientras falten ulteriores avisos dispondrá VS enviar incesantemente el informe de quanto ocurre por la vía de Nápoles duplicándole por Génova.... ${ }^{4}$.

Aunque el Consejo continuase teóricamente vigente hasta finales de $1713^{5}$, no generará ninguna documentación específica. Durante cierto tiempo permanecieron en la capital catalana algunos de sus miembros para resolver los temas pendientes, pero poco más ${ }^{6}$. La documentación conservada en los archivos sardos da fe de una especial intensidad en disposiciones de última hora, concentradas en el mes de marzo de ese año de 1713. Después, tras unos meses de aparente inactividad y vísperas de la constitución del Consejo de España en Viena ${ }^{7}$, se jubilaba, por fin, a los regentes sardos del Consejo de Aragón, Salvador Lochi ${ }^{8}$ y Gaspar Berrueso y Carnicer ${ }^{9}$. Los correspondientes decretos estaban datados en Viena, aunque es de suponer que los regentes ya hacía tiempo que se habían reintegrado a su tierra. De Lochi se diría:

Hacemos saber que en atención a lo bien que nos ha servido el magnifico doctor y Amado nuestro consejero Don Salvador Loquy en la plaza de regente del nuestro supremo Consejo de Aragón por parte de esse Reyno, y a su adelantada edad, cargada

\footnotetext{
3 León SAnz, V.: "Isabel Cristina, reina y regente en Barcelona", trabajo presentado en el Congreso L'aposta catalana a la Guerra de Successió (1705-1707), Barcelona, 3, 4 y 5 de noviembre de 2005, publicado en Cisneros, M., Morales, M., Renom, M. (eds.): L'aposta catalana a la Guerra de Successió (1705-1707), Barcelona, Museu d'Història de Catalunya, 2007, pp. 429-440.

${ }_{4}^{4}$ Archivio di Stato di Cagliari (ASC), Reale Udienza (RU), Classe IV, vol. 67/2, Carte Reali, pp. 310r-310v, 29-V-1713.

5 León Sanz, V.: “El Consejo de Aragón austracista, 1707-1713”, en Ferrero Micó, R., Guia Marín, L. (eds): Corts $i$ Parlaments de la Corona d'Aragó. Unes institucions emblemàtiques en una Monarquia Composta, Valencia, Publicacions de la Universitat de València (PUV), 2008, pp. 239-261.

6 Gran parte de las últimas disposiciones de Isabel Cristina referidas a Cerdeña de marzo de 1713 se encuentran copiadas en ASC, Intendenza Generale (IG), vol. 11.

7 LeÓn SAnZ, V.: "Origen del Consejo Supremo de España en Viena", Hispania, L2/180 (1992), pp. 107-

8 Sobre Salvador Lochi, Guia Marín, L.: Sardegna una Historia pròxima. El regne sard a l'època moderna, Catarroja y Barcelona, ed. Afers, 2012, pp. 281-282.

9 Sobre Gaspar Carnicer, Ibidem, pp. 304-306 y 313-315.
} 142. 
de habituales achaques que le imposibilitan la continuación del mérito que en nuestro real servicio ha contraído, hemos resuelto jubilarlo, como con tenor a las presentes de nuestra cierta ciencia, real y deliberada autoridad le jubilamos, con el goze de todos los honores y prerrogativas que como a tal consejero le pertenecen y de dos mil escudos de plata al año ${ }^{10}$.

De Gaspar Carnicer se argumentarán otros motivos pero igualmente será jubilado ${ }^{11}$. Casi simultáneamente, sin apenas línea de discontinuidad, eran promovidos al Consejo de España, otros dos "sardos"; uno de ellos era José de Silva, conde de Montesanto y marqués de Villasor ${ }^{12}$. El otro era Juan Bautista Cugia, letrado que había desarrollado una dilatada carrera al servicio de la monarquía y que ocupaba a la sazón un cargo en la Real Audiencia sarda ${ }^{13}$.

Aunque parezca paradójico, con estas actuaciones sobre la estructura político-administrativa, que había de servir para gobernar lo que quedaba de la Monarquía Hispánica de los Habsburgo controlada por Carlos de Habsburgo, Cerdeña se vinculaba cada vez más a un espacio italiano que no le había sido propio mientras existió esa Monarquía en todo su esplendor y extensión; ello se producía, entre otras variables, gracias y a través de una administración que sería ejercida durante unos años desde una ciudad tan poco italiana como Viena.

Como consecuencia de la guerra, en los territorios de la Monarquía Hispánica reivindicados por los dos candidatos a la herencia de Carlos II, se estaba marcando una línea de separación que recorría de norte a sur el Mediterráneo occidental, dejando a Cerdeña al este de la misma. Como hemos dicho, para su gobierno y para el de todos aquellos territorios que habían formado parte de la monarquía compuesta de los Austria y que permanecieron en manos del emperador Carlos VI, se instituía en Viena, en enero de 1714, el Consejo de España. Lógicamente los referentes territoriales y políticos más próximos del reino sardo serían a partir de entonces italianos: Milán o el reino de Nápoles ${ }^{14}$; con ese espacio italiano compartirá una misma política de gobierno y tendrá que estrechar y ampliar lazos de todo tipo, también los económicos, sustituyendo en parte aquellos que durante siglos había mantenido con los territorios ibéricos. La llegada de los Saboya en 1720 reforzará ese proceso de italianización que marcará definitivamente su destino.

¿Qué significaron Utrecht y Rastatt en ese escaso cuarto de siglo?. Aparentemente nada si nos atenemos a los resultados inmediatos, pero de alguna manera se abrió

\footnotetext{
10 ASC, Antico Archivio Regio (AAR), vol. H55, 8-I-1714, pp. 12v-14r.

11 “...a la no poca incomodidad, que se le siguirá de mover su casa para venir desde ella a continuar el mérito que en nuestro servicio ha adquirido...", Archivio di Stato di Napoli (ASN), Consiglio di Spagna (CS), vol. 18, 8-I-1714, pp. 1r-4r.

12 Había accedido al título tras la muerte de su suegro Artal de Alagón, ferviente austracista. Artal había vivido muy mal que Felipe V nombrase a Francisco de Castellví, marqués de Laconi, como Grande de España. Este acontecimiento acabó por perfilar los frentes borbónico y austracista en el reino de Cerdeña.

13 Sobre Cugia, Guia, op. cit., (nota 6), pp. 281-284 y 288-289.

14 La documentación referida a estos años conservada en los archivos sardos y en el fondo Consiglio di Spagna del Archivio di Stato di Napoli dan testimonio muy frecuentemente de esta circunstancia. Los virreyes del reino sardo tendrán que mantener una estrecha correspondencia con las máximas autoridades de Milán y Nápoles, especialmente en temas defensivos en los que a la postre dependían de su eventual socorro. A título de ejemplo, véase: nota 84 de este trabajo.
} 
paso la idea de que Cerdeña podía ser desgajada del que había sido su entorno histórico durante casi 400 años, primero la Corona de Aragón y después la Monarquía Hispánica. La isla había pasado a ser moneda de cambio en las cancillerías europeas, desconocedoras e indiferentes a la realidad y las preferencias de la sociedad local. Esta variable importaba poco; el destino de los pueblos no dependía de ellos mismos. En consecuencia el reino sardo va ser considerado un premio de consolación para algún príncipe ansioso de lucir una corona real en una Europa Occidental que buscaba un nuevo equilibrio político y territorial. La sombra imperial contribuyó a mantener la isla a salvo de que ello ocurriese en Utrecht y Rastatt. Una sombra que sólo fue efectiva en las últimas fases de las negociaciones que dieron lugar a ambos tratados. La disolución de los lazos del reino sardo con los territorios "hispánicos" que habían quedado en manos del emperador tendría que esperar y se precipitaría años más tarde a partir de $1717^{15}$.

Hasta esas fechas parecía que los vínculos de Cerdeña con la Corona de Aragón, inmersa en la Monarquía Hispánica, y con sus monarcas eran tan fuertes que se mantenían más allá de la propia existencia de esa corona y de que el monarca que se arrogaba su herencia no reinase en Madrid o Barcelona, sino en Viena. Lejos quedaban las palabras de Felipe II en las que, en el contexto de negociaciones territoriales, afirmaba la imposibilidad de desmembrar Cerdeña de la Corona de Aragón ${ }^{16}$. A pesar de la distancia en el tiempo, el sentimiento de los isleños seguía igual de firme que en la segunda mitad del siglo XVI. Para los sardos de finales del siglo XVII o principios del siglo XVIII no cabía imaginar un escenario en el que el reino sardo no formase parte de la monarquía Hispánica. De alguna manera, con su vinculación con Viena, ese requisito se seguía manteniendo en tanto en cuanto su rey, el emperador Carlos VI, se consideraba el legítimo monarca de esa corona, y además la estructura política del reino, conformada en el seno de la Corona de Aragón, se estaba manteniendo incólume a lo largo del conflicto sucesorio gracias precisamente a la política austracista.

A principios del siglo XVIII la diplomacia internacional impondrá nuevos criterios. Como decíamos, Cerdeña estaba en el "mercado" y acabará por ser sacrificada en nombre del equilibrio inaugurado en Utrecht y Rastatt, aunque fuese unos años más tarde. El propio emperador no dudará en intercambiarla con Sicilia, en la coyuntura de 1717-1720, evidenciando cuales eran sus verdaderos intereses más allá de las promesas de no abandonar a sus súbditos sardos.

$$
* * *
$$

15 Aunque formalmente la cesión del reino de Cerdeña por el emperador a Vitorio Amedeo de Saboya no se producirá hasta 1720, la invasión de Felipe V en 1717 marcó un antes y un después en la historia sarda, no tanto por el decreto de Nueva Planta del Borbón que homologaba Cerdeña a los otros países ibéricos, sino porque la vinculación de Cerdeña con Carlos de Austria se truncó bruscamente. Con ello lo que quedaba de la antigua estructura de gobierno que había relacionado secularmente al reino sardo con sus monarcas hispánicos desaparecía de manera definitiva.

16 Manconi, F.: “'De no poderse desmembrar la Corona de Aragón'. Sardenya i Països Catalans, un vincle de quatre segles", Pedralbes, 18 (2), (1998), pp. 179-194. Este trabajo ha sido publicado recientemente con otros del mismo autor en Manconi, F.: Una piccola provincia di un grande impero. La Sardegna nella Monarchia composita degli Asburgo (secoli XV-XVIII), Cagliari, CUEC, 2012, pp. 92-121. 
Estos primeros veinte años del siglo XVIII en el reino de Cerdeña han permanecido durante mucho tiempo en una relativa oscuridad historiográfica. En otras ocasiones he intentado explicar, explicarme, cuales han sido las variables para que ello hubiese ocurrido $^{17}$. Para la historiografía italiana en general la historia de la isla ha importado poco, siendo como era un reino demasiado hispanizado para integrarlo en el discurso de la nación italiana; en todo caso cuando se quiso incorporar su historia al conjunto de la historia de Italia se hizo siempre recurriendo a determinados prismas que desenfocaban el verdadero encaje del reino sardo en la Corona de Aragón y en la Monarquía Hispánica: Cerdeña habría sido simplemente un reino dominado por una monarquía extranjera.

Por lo que respecta a la historiografía española el olvido ha sido más sangrante. En los discursos de historia de España parecía obviarse de manera premeditada cualquier referencia. No podemos admitir que ello se debiese exclusivamente a que se trataba de un reino menor y por tanto poco influyente en la trayectoria de la Monarquía Hispánica; más bien pienso, y es aventurarme en derroteros muy subjetivos, que de alguna manera se trataba de olvidar la perdida del reino; ¿humillante?, ¿doloroso?, ¿poco conveniente para la construcción de un discurso unitarista de la nación españo-

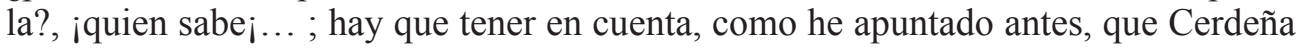
era el territorio con más alto grado de hispanización de todos aquellos que España "perdió" en Europa (utilizando una terminología anclada en el pasado). Evidentemente "asumir" con naturalidad la "pérdida" podía dinamitar categorías consideradas inmutables en el discurso aludido.

Lo más grave es que la historiografía dedicada a la Corona de Aragón ha cometido el mismo error. Más allá de glosar las grandes gestas de la expansión catalano-aragonesa en la época medieval, con un resabio imperialista, ha obviado, con honrosas excepciones ${ }^{18}$, reflexionar sobre el papel del reino sardo no solo en la construcción sino también en la pervivencia de la Corona de Aragón en el seno de la Monarquía Hispánica. Incluso la mayoría de historiadores que blasonan de una sensibilidad "nacionalista", cuando hacen historia de la Corona de Aragón en época moderna, lo hacen limitándose a los territorios ibéricos, aquellos que forman parte del actual estado español; se les podría recordar que con ello están haciendo exclusivamente historia de España, aunque posiblemente no fuese esa su intención.

Tras esta digresión, que alguien podría tachar de poco académica y un tanto amarga, quiero dejar claro que la Historia de Cerdeña es una asignatura pendiente no solo en los discursos sobre la Historia de la Corona de Aragón, sino en los discursos de Historia de España. No se puede entender la Corona de Aragón sin el reino sardo; no tanto por la dimensión territorial o económica del mismo sino por el carácter de los lazos establecidos con el núcleo expansivo y su capacidad de transformarlo desde la

17 Guia Marín, L.: "Un destino imprevisto para Cerdeña. De los Habsburgo a los Saboya”, en ÁlvarezOssorio, A., García García, B., León Sanz, V. (coords.): La pérdida de Europa. La Guerra de Sucesión por la Monarquía de España, Madrid, Fernando Villaverde Ediciones, 2007, pp. 755-784.

18 Tal es el caso de la obra coordinada por Ernest Belenguer en la que aparece un extenso capítulo dedicado al reino de Cerdeña de Francesco Manconi. Manconi, F.: "El regne de Sardegna: de Ferran el Catòlic al decret de Nova Planta", en Belenguer CebriÀ, E. (coord.): Història de la Corona d'Aragó. L'època moderna (14791715). Ferran II i els Austria, Barcelona, Edicions 62, 2007. 
periferia. De igual manera no se puede entender la historia de España sin considerar la existencia del reino de Cerdeña; ¿alguien se ha preguntado por el hecho de que las grandes casas nobiliarias españolas siguieron siendo poseedoras, bajo los Saboya, de grandes feudos en Cerdeña que abarcaban la mayoría de la isla hasta la liquidación del régimen señorial en el siglo XIX?, ¿se puede entender la trayectoria de la nobleza española durante disolución del Antiguo Régimen, sin analizar su relación con los vasallos sardos?. No es este el lugar para extendernos sobre ello; nuestra intención es exclusivamente reivindicar la historia de Cerdeña como una de las claves para ayudar a interpretar la historia del núcleo central de la que fuera monarquía compuesta de los Austrias y después monarquía española de los Borbones.

Decía también, cuando reflexioné sobre la historiografía referida a Cerdeña, que ha sido gracias a los historiadores sardos, conscientes de pertenecer a una comunidad histórica muy consolidada, el que dispongamos en la actualidad de un amplio repertorio de estudios. La necesidad de reflexionar sobre la historia de la isla arranca de cuando el reino existía como tal y llega hasta nuestros días, aunque lógicamente las diferencias metodológicas sean enormes. Quizás habría que destacar que entre los historiadores sardos siempre se ha sentido la necesidad de encajar la historia local en los entornos políticos de los que la isla formó parte. De alguna manera esa necesidad ha propiciado, en la actualidad, que desde los centros sardos de investigación superior (Universidades de Cagliari y Sassari, y Istituto di Storia dell'Europa Mediterranea del CNR) se hayan abierto vías de contacto y cooperación con la historiografía española. Esta clara voluntad de superar tópicos y luoghi comuni de la historiografía tradicional por parte los historiadores sardos, ha propiciado que paulatinamente la presencia de especialistas en la historia de Cerdeña se haya hecho habitual en los encuentros científicos de los últimos años; a su vez en la isla se han generado numerosas actividades ${ }^{19}$ con presencia de historiadores españoles, que están permitiendo que la anterior invisibilidad de la realidad sarda esté en vías de superación.

A pesar de todo ello, la historia de Cerdeña en los años que nos ocupan del primer cuarto del siglo XVIII, que fueron especialmente ignorados por la historiografía, sigue recibiendo poca atención por parte de los historiadores locales. Tradicionalmente, los modernistas sardos, si han dedicado sus preferencias al encaje de Cerdeña en la Monarquía compuesta de los Austria, concluyen su análisis con la muerte de Carlos $\mathrm{II}^{20}$; si sus investigaciones se han encaminado al estudio del siglo XVIII, 1720 se convierte en una fecha emblemática a partir de la cual construyen todo su discurso, como si la llegada de los Saboya fuese una especie de acta de nacimiento del reino sardo ${ }^{21}$. Precisamente los actos de la cesión y de los primeros meses de la administración pia-

19 Entre ellas cabe destacar, AnAtra, B., Manconi, F. (coords.): Sardegna, Spagna e Stati italiani nell'età di Filippo II, Cagliari, AMD Edizioni, 1999; AnAtra, B., Manconi, F. (coords.): Sardegna, Spagna e Stati italiani nell'età di Carlo V, Roma, Carocci, 2001; Anatra, B., Murgia, G. (coords.): Sardegna, Spagna, Mediterraneo dai Re Cattolici al Secolo d'Oro, Roma, Carocci, 2004.

20 Anatra, B.: La Sardegna dall'unificazione aragonese ai Savoia, Torino, Ed. UTET, 1987; AnATrA, B., Mattone, A., Turtas, R.: Storia dei Sardi e della Sardegna, vol. III, L'Età moderna. Dagli Aragonesi a la fine del dominio spagnolo, Milano, Ed. Jaca Book, 1989; MAnconi, F.: Cerdeña, un reino de la Corona de Aragón bajo los Austrias, Valencia, PUV, 2010.

21 Sotgiu, G.: Storia della Sardegna sabauda, Roma, Ed. Laterza, 1984; Scaraffia, L.: La Sardegna Sabauda, Torino, Ed. UTET, 1987. 
montesa motivaron, en la primera mitad del siglo XX, estudios que siguen aportando una información valiosísima para el análisis de la época anterior ${ }^{22}$. Más recientemente el trabajo de Maria Lepori constituye una visión especialmente interesante sobre las relaciones de las elites sardas con los Saboya, a partir de la cesión ${ }^{23}$.

Veinte años de historia sarda, coincidentes con la Guerra de Sucesión y los tratados que ayudaron a superar el conflicto, quedan en una especie de limbo. Los estudios de más entidad proceden casi todos de historiadores foráneos a Cerdeña. Hace años Miguel Ángel Alonso Aguilera publicó su libro sobre la invasión de 1717 y la segunda administración borbónica ${ }^{24}$. Quizás la atracción por los temas relacionados con la Nueva Planta en España ayudase a que ese periodo recibiese también la atención de otros especialistas, siempre españoles, que analizaron la Nueva Planta introducida por Felipe $\mathrm{V}$ en la isla tras la invasión ${ }^{25}$. De los años inmediatamente anteriores no ha habido casi estudios de interés, excepción hecha de los trabajos de Pedro Voltes $\mathrm{Bou}^{26}$; solo alguna aportación menor rompía el silencio historiográfico en la isla sobre este periodo y daba noticia de documentos puntuales ${ }^{27}$. Las apreciaciones que en su día vertió Loddo Canepa sobre la imposibilidad de investigar sobre el llamado periodo austriaco por falta de una documentación ${ }^{28}$, supuestamente expoliada por la administración al servicio de Viena, es posible que contribuyesen a desanimar a nuevos investigadores a adentrase en unos años cruciales para el futuro de Cerdeña.

22 Cabe destacar: La RoccA, L.: "La cessione del Regno di Sardegna alla Casa Sabauda. Gli atti diplomatici e di possesse con documeti inediti” en Miscellanea di Storia italiana, Deputazione di Storia Patria, XLI (1905), Torino, pp. 117-239; Loddo Canepa F.: Dispacci di Corte, Ministeriali e Vice-regi concernenti gli affari politici, giuridici ed ecclesiastici del Regno di Sardegna (1720-1721), Roma, Società nazionale per la Storia del Risorgimento italiano, 1934. Más recientemente cabe reseñar, GiRGENTI, A.: "Vittorio Amedeo II e la cessione della Sardegna: Trattative diplomatiche e scelte politiche”, Quaderni di Storia, 40, (1994), pp. 677-704.

23 Lepori, M.: Dalla Spagna ai Savoia. Ceti e Corona nella Sardegna del settecento, Roma, Carocci, 2003.

24 Alonso Aguilera, M. A.: La conquista y el dominio español de Cerdeña (1717-1720). Introducción a la política española en el Mediterráneo posterior a la Paz de Utrecht, Valladolid, Universidad de Valladolid, 1977.

25 Sobre la Nueva Planta en Cerdeña, Bermejo Cabrero, J. L.: "Un decreto más de Nueva Planta", Revista del Departamento de Derecho Político, UNED, 5, (1979-1980), pp.129-144; Escartín SÁnchez, E.: "Notas sobre la Nueva Planta en Catalunya y Cerdeña (1717-1720)", en Meloni, M. G., SchenA, O. (coords.): La Corona d'Aragona in Italia (secc. XIII-XVIII), Sassari y Roma, Carlo Delfino Editore, 1997; MAQUEDA ABreU, C.: "En torno al decreto de Nueva Planta de Cerdeña. 1717-1720", Ius Fugit, 13-14, (2004-2006), pp. 439-477; Pérez Marcos, R. M.: "Estrategias de gobierno y modelos de administración en la Nueva Planta de Cerdeña", en Escudero López, J. A. (coord.): Génesis territorial de España, Zaragoza, El Justicia de Aragón, 2007, pp. 549-578.

26 Voltes Bou, P.: "Noticias sobre las mercedes nobiliarias otorgadas por el Archiduque Carlos de Austria durante su gobierno en Barcelona", Hidalguía, 22 -23, (1957), pp. 321-336 i 506-544; Voltes Bou, P.: "Aportaciones a la Historia de Cerdeña y Nápoles durante el dominio del Archiduque Don Carlos de Austria", Estudios de Historia Moderna, 1, (1951), pp. 48-128.

27 Pala, G.: L'occupazione austriaca della Sardegna attraverso alcuni documenti del British Museum, Cagliari, Gia, 1978; ErA, A.: 'Diari sardi inediti degli anni 1708, 1717-18, 1720", en Studi Storici in onore di Francesco Loddo Canepa, Firenze, G. C. Sansoni, 1959, vol. 2, pp. 217-236; Pena SueIro, N.: "Dos relaciones de sucesos sobre la toma de Cerdeña (1708)", en PABA, A. (ed.): Encuentro de Civilizaciones (1500-1750): Informar, narrar, celebrar, Madrid, Universidad de Alcalá, 2003, pp. 352-364; Del Piano, L.: "Una relazione inedita sulla Sardegna nel 1717”, Archivio Storico Sardo, 24, (1964), pp. 161-192.

28 Loddo Canepa, F.: La Sardegna dal 1478 al 1793, vol. 1. Gli anni 1478-1720, Cagliari, Ed. Gallizzi, 1976. 
Quizás también habría que buscar explicaciones históricas, que tienen connotaciones psicológicas, en esta actitud negativa respecto a todo lo que tuviese que ver con Viena. No en balde Austria acabó por convertirse en la enemiga ancestral de la unidad de Italia y este hecho marcó durante mucho tiempo las aproximaciones historiográficas a cualquier periodo de su historia. Las aportaciones recientes de mayor entidad sobre la historia sarda, coincidente en el tiempo con las negociaciones de Utrecht y Rastadt, proceden en su mayoría de historiadores foráneos. Entre ellos caben destacar los trabajos de Mario Döberl ${ }^{29}$ y Lluís Guia ${ }^{30}$. Solo recientemente la trayectoria interna del reino en esta encrucijada histórica ha llamado la atención de historiadores sardos como es el caso de F. Manconi ${ }^{31}$ y G. Murgia ${ }^{32}$.

Por encima de ese erial historiográfico sobre la historia local, la coyuntura de Utrecht y su repercusión en la cesión del reino de Cerdeña ha merecido sendos trabajos, separados en el tiempo, de gran interés. La autoría del primero de ellos, publicado hace más de 20 años, se debe a Antonello Mattone ${ }^{33}$; aunque se centra sobre todo en la cesión del reino a los Saboya y su trayectoria posterior durante el siglo XVIII, analiza la coyuntura internacional de los años inmediatamente anteriores partiendo del Tratado de Utrecht. El segundo trabajo que queremos resaltar es de reciente factura y se debe a la profesora alemana Sabine Enders ${ }^{34}$; su estudio se centra en la edición y análisis de una obra anónima, La Sardegna. Paranimfa de la Pace, que atribuye a Vicente Bacallar y Sanna; esta obra gira en torno a las negociaciones de Utrecht y la frustrada adjudicación del reino al elector de Baviera. Según la editora:

Il libro descrive la situazione politica durante la conferenza di pace dal punto di vista della Sardegna e non come di consueto dal punto di vista di una delle grandi potenze europee. Francia, Spagna, Austria Germania, Olanda e Inghilterra, e questo fatto è di per sé abbastanza singolare. La diplomazia delle grandi potenze sviluppò un piano per la sovranità della Sardegna con un re che avesse la residenza nell'isola, e questo obiettivo, anche con l'aiuto della Sardegna, alla fine del 1713, sembrava in procinto di poter essere realizzato ${ }^{35}$.

$$
* * *
$$

29 DöBerl, M: "Es menester conservar los buenos y abatir los malos", la situazione nel regno di Sardegna nel 1711 descritta e analizzata da Juan Amor de Soria", Cooperazione Mediterránea, 1-2 (2003), pp. 183-217; DöBerL, M.: "La visita generale di Marcos Marañón y Lara nel regno di Sardegna (1714-1715). Un breve periodo di riforme sotto il governo degli Asburgo austriaci", Estudis. Revista de Historia Moderna, 33, (2007), pp. 225-253.

30 GUIA, op. cit., (nota 6).

31 Manconi, F.: "Cerdeña a finales del siglo XVII-principio XVIII: una larga crisis de casi medio siglo", Estudis. Revista de Historia Moderna, 33, (2007), pp. 27-44.

32 Murgia, G.: "La Sardegna durante la dominazione austriaca in una relazione di un anonimo, precursore del riformismo sabaudo nell'isola", Annali della Facoltà di Scienze della Formazione dell'Università di Cagliari, Nuova Serie, 27, (2004), pp. 169-236.

33 Mattone, A.: "La cessione del Regno di Sardegna dal trattato di Utrecht alla presa di possesso sabauda (1713-1720)", Rivista Storica Italiana, CIV-I (1992), pp. 5-89.

34 Enders, S. (ed.): Vicente Bacallar, La Sardegna Paraninfa della Pace e un piano segreto per la sovranità 1712-1714, Stuttgart, Giuanne Masala, 2011.

35 Ibidem, pp. 16. 
Después de la muerte de Carlos II, al igual que en la mayoría de los territorios de la monarquía, en Cerdeña fue reconocido como monarca Felipe de Borbón. La historiografía sarda calificó, diríamos que por omisión, los años inmediatamente posteriores, entre 1700 y 1708, como la continuación del periodo español pero sin abordar el análisis de los mismos. De hecho numerosos estudios toman la fecha de 1700 como referencia final, estableciendo una línea de discontinuidad artificial entre el "todo" y la "nada" ${ }^{36}$. Las diversas etapas del conflicto sucesorio indujeron a calificar como "segundo periodo español", los años comprendidos entre 1717 y 1720, identificando con cierta arbitrariedad Borbón con español. El periodo intermedio, entre 1708 y 1717, fue calificado de "dominio austriaco" ya que Carlos de Austria acabó siendo emperador en Viena a partir de 1711. Una terminología, imbuida de un gran presentísmo que ignoraba que durante gran parte de esos años el gobierno fue ejercido desde Barcelona y que cuando se hizo desde Viena no se perdió nunca el carácter "hispánico" en las normas y los hombres de gobierno ${ }^{37}$. No vamos a entrar en el debate de una terminología obsoleta, o en las filias y fobias que se manifestaron en aquellos historiadores al compás de acontecimientos muy posteriores que tenían como telón de fondo la construcción de la unidad italiana, en la que Austria, como hemos apuntado, jugó el papel de secular enemigo. Sólo nos interesa ahora destacar dos cosas: que más allá de Utrecht y Rastatt, Cerdeña se mantuvo, sin solución de continuidad, en manos del emperador Carlos VI; y que, a pesar de toda una historiografía posterior que demonizó su reinado, Carlos no fue peor que Felipe o que los monarcas de la casa de Saboya.

Como hemos dicho la incorporación de Cerdeña a la causa austracista había sido tardía, en 1708, cuando las armas Carlos en la península ibérica habían sufrido ya su primera gran derrota en Almansa, el 25 de abril de 1707. El ritmo de la Guerra al otro lado del mar había seguido una secuencia inversa: Carlos de Austria y sus aliados habían ido consolidando su dominio paulatinamente y expulsando a los borbónicos, primero de Milán en 1706, y después del reino de Nápoles en julio de 1707. El destino de Cerdeña, que adquiría de golpe y de repente una renovada importancia estratégica ${ }^{38}$, parecía irremediablemente destinado a ser objeto de deseo en los intereses en conflicto. A nadie extrañó que la flota aliada, al mando del almirante Lake, se presentase frente a sus costas en el verano de 1708 y, tras una débil y descoordinada

36 Sobre esta fisura de 1700 en la mayoría de los trabajos sobre la época hispánica de Cerdeña, GUiA Marín, L.: "Tiempo de Mudanza. Los oficiales reales en el reino de Cerdeña al inicio del Setecientos", en González Cuerva, R., Martínez Millán, J. (coords.): La Dinastía de los Austria. Las relaciones entre la Monarquía Católica y el Imperio, Madrid, Editorial Polifemo, 2011, vol. 3, pp. 1627-1662.

37 Hay que hacer constar que algunos historiadores no han dudado en calificar los 20 primeros años del siglo XVIII como parte del "periodo español” sin dejarse arrastrar por una periodización obsoleta. Me refiero a Raimondo Turtas que en uno de los manuales colectivos sobre la historia de Cerdeña, relativamente reciente, ha distinguido claramente, en su contribución sobre la historia de la Iglesia en Cerdeña, "Il periodo spagnolo (1479-1720)" de "Il periodo sabaudo (1720-1861)” en TurTas, R.: "La Chiesa sarda dal periodo spagnolo all'Ottocento", en Brigaglia, M., Mastino, A., Ortu, G. G.: Storia della Sardegna. 2. Dal Settecento a oggi, Roma-Bari, Editori Laterza, 2006.

38 Según Francisco Castellví el 16 de febrero de 1707 ya se había decidido, en Consejo de Estado, conquistar Cerdeña, Castellví, F.: Narraciones Históricas (I, II, III y IV), Madrid, Ed. Fundación Elías de Tejada y Erasmo Pèrcopo, 1997, vol. 2, p. 343. El mismo autor cita que Peterborough, desde Turín el 27 de abril de 1707, insistía en la importancia de ocuparla, Ibidem, p. 442. 
resistencia, tomase posesión de la isla. El entorno de Felipe de Borbón no dio su apoyo para que desde la isla se organizase la resistencia y se hiciese frente a la armada austracista. La indolencia del virrey, para desesperación de algunos borbónicos como Vicente Bacallar ${ }^{39}$, hizo el resto.

Sin duda, la intervención aliada fue determinante y permitió a Carlos de Austria incorporar Cerdeña al bando austracista; si esto resulta absolutamente cierto, también es verdad que en el seno de la sociedad sarda habían aflorado, a la par del conflicto sucesorio, unos enfrentamientos, que afectaban especialmente a las élites y que se retrotraían a acontecimientos de la centuria anterior. Estas divisiones propiciaron y facilitaron igualmente el triunfo austracista. Ambos bandos, que a su vez no estaban exentos de fisuras internas, habían mostrado abiertamente sus filias y fobias en la encrucijada del cambio dinástico; nada original si lo comparamos con los otros escenarios territoriales de la monarquía. En el caso de Cerdeña, sin embargo, al tratarse de una sociedad pequeña las fracturas recorrían, no siempre de manera unívoca, las mismas parentelas. Como si de estrategias familiares se tratase encontraremos partidarios de uno u otro aspirante en entornos muy próximos, de tal manera que, superados los enfrentamientos puntuales, e incluso, con una perspectiva de mayor alcance, el conflicto global, la recomposición de las élites será relativamente rápida sin que se produjesen sustituciones traumáticas de las mismas. Aunque sea una digresión, que nos aleja de la coyuntura del triunfo austracista de 1708, se podría afirmar que Cerdeña saldría finalmente del conflicto sin demasiadas heridas en las elites dominantes; a partir de 1720 unos y otros recuperaron sus títulos y haciendas, eso sí como súbditos de un monarca, el Saboya, que mantuvo una desconfianza generalizada hacia la nobleza, no solo la radicada en la isla, sino especialmente los grandes títulos que desde la España de Felipe V, y en menor medida desde Viena, siguieron detentando sus feudos sardos.

En esas élites sardas destacaron, por méritos propios, personajes notables. Hemos citado a alguno de ellos como el conde de Montesanto, marqués de Villasor, que llegaría a ser presidente del Consejo de España de la corte de Viena tras la muerte del arzobispo de Valencia, primer ocupante del cargo. En torno a él se aglutinaría todo el partido "austriaco". En el polo opuesto se situaría Francisco de Castellví y Dexart ${ }^{40}$, marqués de Laconi, nombrado grande de España en los inicios del reinado de Felipe $\mathrm{V}^{41}$. Francisco era hijo del asesinado Agustín de Castellví, referente de las élites sardas en su confrontación con la Monarquía Hispánica en los inicios del reinado de

39 En sus memorias, V. Bacallar escribirá profusamente sobre las circunstancias de la perdida de Cerdeña y la incomprensible política del ministro Amelot ("Amelot despreció no el riesgo, sino el reino, porque decía importaba muy poco a la Monarquía, y que servía más de gasto que de útil, si se había de presidiar", BACALLAR y Sanna, V.: Comentarios de la guerra de España e historia de su rey Felipe V, El Animoso , por Don Vicente Bacallar y Sanna, Marqués de San Felipe, Edición y estudio preliminar de Seco Serrano, C. Madrid, Biblioteca de Autores Españoles, 1957, pp. 148-149). Castellví, remedando a Bacallar, refiere el mismo hecho “Amelot, primer ministro en España, despreció no el riesgo sino el reino”, en CASTELlví, op. cit., (nota 35), vol. 2, p. 549. Sobre la campaña de 1708 en Cerdeña, GuIA, op. cit., (nota 15).

40 Sobre el marqués de Laconi, GuiA, op. cit., (nota 6), pp. 123-124.

41 GuiA, op. cit., (nota 15). 
Carlos II ${ }^{42}$; por ello fue considerado por algunos como "padre de la patria" sarda; su muerte había desencadenado la crisis Camarasa ${ }^{43}$, tras la cual la afirmación del poder del último monarca Habsburgo en la isla alcanzó límites nunca conocidos. Paradójicamente su hijo acabará siendo un ferviente partidario de una dinastía, la borbónica, destinada a conseguir un mayor avance del absolutismo. Paradoja relativa ya que la adscripción a uno u otro bando siguió derroteros mucho más complejos que ahora no podemos analizar.

El más emblemático de todos aquellos personajes que tomaron partido por uno $\mathrm{u}$ otro candidato fue quizás Vicente Bacallar y Sanna. Testigo directo de gran parte de los acontecimientos bélicos que vivió la isla en esos años, se convertirá en el principal cronista de la contienda al servicio de Felipe de Borbón ${ }^{44}$. Personaje de una gran cultura fue el máximo exponente del alto grado de hispanización que tenia el reino sardo en los albores del siglo XVIII ${ }^{45}$. Ocuparía importantes cargos en la administración regnícola ${ }^{46}$ y posteriormente llegaría a ejercer de embajador de Felipe $V$ en Génova y la Haya. Posiblemente fue uno de los pocos miembros de las élites que estuvo al tanto de los proyectos de cesión de la isla en la coyuntura de Utrecht ${ }^{47}$. Debió de asumir por pragmatismo y con una necesaria fatalidad las, al parecer, irremediables decisiones sobre el futuro de Cerdeña; decisiones acordadas por casi todas las potencias en las negociaciones para poner fin a un conflicto cuyos escenarios principales habían estado muy alejados de la isla y habían afectado a gran parte de la Europa occidental. En cualquier caso, superado el "peligro" de la cesión, siguió siendo un ferviente servidor de Felipe $\mathrm{V}$ y colaboró, cuando no estuvo entre los promotores, en cualquier empresa que previese el retorno del dominio borbónico a Cerdeña. Lo había hecho en 1710, incluso puede que apoyase la proyectada invasión de 1714, inspirada por el elector de Baviera, y sin duda participó directamente en la invasión borbónica de $1717^{48}$.

Durante las negociaciones que se inauguraron en Europa en todos los frentes diplomáticos para poner fin a la Guerra de Sucesión y abrir la puerta a un nuevo equilibrio europeo, Cerdeña parecía vivir en una burbuja, alejada de todo sobresalto. La sociedad sarda seguía sin conocer cambios bruscos a nivel interno, más allá de la sucesión de monarcas en función de la suerte de las armas. Quizás se trataba de una engañosa continuidad que enmascaraba cambios profundos en el exterior que acabarán por trastocar la trayectoria del reino sardo; cambios que incluían la idea de que la isla

42 Manconi, F.: “Don Agustín de Castelví, "padre della patria” sarda o nobile-bandolero?”, en Manconi, F. (coord.): Banditismi Mediterranei. Secoli XVI-XVII, Roma, Ed. Carocci, 2003, pp. 107-146.

43 La obra clásica sobre estos acontecimientos se debe a ScAnO, D.: "Donna Francesca di Zatrillas, marchesa di Laconi e di Sietefuentes”, Archivio sardo, XXIII (1946). Las aportaciones más recientes y novedosas se encuentran en MANCONI, op. cit., (nota 18), pp. 465-498.

44 Bacallar, op. cit., (nota 37).

45 Vicente Bacallar fue uno de los miembros fundadores de la Real Academia de la Lengua española, escribiendo la mayor parte de sus libros en esta lengua.

46 Bacallar, junto con su padre, había formado parte del circulo más próximo del último virrey de Carlos II, el conde de Montellano; una camarilla que generaría enemigos en la sociedad local pero que permitiría a Vicente Bacallar el acceder al cargo de Gobernador general de Cagliari en tiempos de Felipe V, cargo que ostentaba en 1708 .

47 Según Sabine Enders Bacallar estuvo al tanto y acabó siendo un ferviente partidario de la proyectada cesión del reino sardo al elector de Baviera, EndERs, op. cit., (nota 32).

48 Alonso, op. cit., (nota 22). 
podía ser pieza de cambio ${ }^{49}$. En cualquier caso, si nos atuviésemos exclusivamente a lo que nos trasmite la documentación conservada en sus archivos Cerdeña fue el único territorio de la Corona de Aragón que conservó gran parte de su contexto jurídico, político e institucional más allá de la guerra. Cuando fueron abolidos los fueros de Aragón y Valencia y suprimido el Consejo de Aragón en 1707, Cerdeña, todavía Borbónica, solo se vio afectada de manera muy superficial: por decisión de Felipe V debería pasar a ser gobernada a través del Consejo de Italia ${ }^{50}$, junto con Mallorca, pero no hubo ninguna medida que cuestionase sus fueros, costumbres, usos, etc. y su estructura político-institucional interna. Por tanto lo único que cambió, en esa precisa coyuntura que apenas duró un año, es que su relación con el monarca habría de vehicularse a través de otro Consejo y no a través del Consejo de Aragón, ya desaparecido.

Cuando, tras la intervención de la armada aliada, el reino sardo pasó al bando austracista, la "normalidad" fue restablecida, Cerdeña pasaría de nuevo a ser gobernada a través del Consejo de Aragón; se trataba sin embargo del Consejo de Aragón austracista que venía funcionando en paralelo desde $1705^{51}$ y que como hemos dicho continuará haciéndolo hasta la primavera de 1713. Miembros destacados de las élites pasaron a servir en el Consejo, ocupando las correspondientes plazas de regentes o de secretario de los papeles de Cerdeña; hemos citado previamente a Gaspar Carnicer y a Salvador Lochi, pero también cabe destacar a Jerónimo Santjust, miembro de una de las más acrisoladas familias de la nobleza local, que mantenía a la mayoría de sus miembros en el bando borbónico ${ }^{52}$. El Consejo mantenía, gracias a la incorporación de Cerdeña en 1708, su razón de ser; prácticamente sus deliberaciones se centraron en gran parte sobre los asuntos sardos ya que, al estar la corte asentada en Barcelona, los asuntos referidos a Cataluña siguieron otro iter administrativo. Sin duda la desaparición del Consejo en 1713 y la subsiguiente creación del Consejo de España tuvo un carácter extraordinario, pero ello no significó, repito, ningún cambio significativo en los mecanismos de relación del reino con su monarca; los modelos utilizados a partir de entonces fueron los mismos que antaño; sólo había cambiado el consejo de referencia y la ciudad en donde tenía su sede. Hubo, eso si, que resolver temas puntuales, como la contribución que Cerdeña habría de aportar a la financiación del nuevo consejo y el organigrama de oficiales que se habrían de incorporar al mismo. Todo ello contribuyó a reforzar el papel de Cerdeña en el seno del Consejo de España, a hacerla más visible y a establecer una relación más estrecha entre el emperador y el pequeño reino insular; una relación que parecía plenamente consolidada y a prueba de cualquier contrariedad. Es evidente que con el paso de los años la situación de

\footnotetext{
49 Mattone, op. cit., (nota 31).

50 Arrieta Alberdi, J.: “Austriacistas y borbónicos entre los altos magistrados de la Corona de Aragón (1700-1707)", Pedralbes, 18 (2), (1998), pp. 275-297; "Notas sobre la presencia de Cerdeña en el Consejo Supremo de la Corona de Aragón”, en XIV Congresso di Storia della Corona d'Aragona, Sassari, Ed. Carlo Delfino, 1997, vol. 4, pp. 11-25.

51 León SAnz, V.: La Guerra de Sucesión española a través de los consejos de Estado y Guerra del archiduque Carlos de Austria, Madrid, Universidad Complutense, 1989; y Entre Austrias y Borbones. El Archiduque Carlos y la Monarquía de Espanya (1700-1714), Madrid, Ed. Sigilo, 1993.

52 Sobre Jerónimo Santjust, GuiA, op. cit., (nota 6), pp. 349-351.
} 
"continuidad" institucional hubiera cambiado pero para Cerdeña no hubo tiempo, de tal manera que hasta 1717 todo parecía desarrollarse sin convulsiones internas.

Tampoco los tribunales del reino, entre ellos la Real Audiencia, conocieron cambios relevantes; en todo caso, si los hubo, fueron siempre de algunos de sus protagonistas, nunca de su ámbito territorial de actuación, de su organización o de sus procedimientos ${ }^{53}$. Asimismo la institución virreinal siguió plenamente vigente conservando su preeminencia, sus funciones y su carácter emblemático ${ }^{54}$, aunque sería exagerado hablar de esplendor en un reino "pobre" como el sardo; resulta significativo que se mantuvo siempre reservada a los grandes nobles ibéricos, ni siquiera con participación de los austriacos o de los italianos en tiempos de Carlos de Austria.

El patronato real sobre la iglesia sarda continuó permitiendo a este monarca la designación de sus jerarquías entre eclesiásticos de la órbita hispánica ${ }^{55}$; en el caso de las ordenes religiosas se mantuvieron la mismas provincias que miraban preferentemente hacia la Corona de Aragón en particular y al contexto hispánico en general. Solo con los Saboya se iniciaría el cambio en la organización territorial de las mismas $^{56}$. Por ello muchos eclesiásticos regulares austracistas de la Corona de Aragón ibérica, cuando hubieron de exiliarse, encontraron acogida de manera natural en Cerdeña, en los que no dejaban de ser conventos de su misma provincia; por ello no se puede hablar en su caso de exilios en Italia pues Cerdeña, a diferencia de Nápoles o Milán, no pertenecía todavía al espacio italiano.

La nobleza local, fuertemente hispanizada, mantuvo su potencialidad organizativa en los foros estamentales; si bien, aunque estos fueron poco operativos, continuaron formalmente vigentes durante todo el conflicto y más allá del mismo. Pero quizás el mayor signo de continuidad en Cerdeña fuese la pervivencia de su régimen munici$\mathrm{pal}^{57}$, que mantuvo el modelo catalano-aragonés en sus estructuras organizativas y en el mecanismo de acceso a los cargos de gobierno, conocido como insaculación; un régimen municipal que había sido uno de los principales objetivos a batir por Felipe V en los reinos ibéricos de la Corona de Aragón. Sin duda Carlos de Austria mantuvo Cerdeña, con el resto de los territorios hispánicos que controló, en una estructura política de monarquía compuesta que pretendía dar continuidad a la Monarquía Hispánica en descomposición. Con ello la idiosincrasia de Cerdeña y su pertenencia a esa monarquía parecía perpetuarse aunque fuese gobernada por un monarca que acabará por no residir ni en Madrid ni en Barcelona.

Una inercia, una continuidad en la Cerdeña de Carlos de Austria que hemos calificado de engañosa y no tanto por que a nivel interno se estaban produciendo también algunos cambios subliminales que hubieran acabado por modificar el contexto

53 GUIA, op. cit., (nota 34).

54 Mateu Ibars, J.: Los virreyes de Cerdeña. Fuentes para su estudio, Padova, Cedam, 1968.

55 Turtas, R.: Storia de la Chiesa in Sardegna. Dalle origini al 2000, Roma, Città Nuova, 1999.

56 Resulta de gran interés el proceso de la creación de la provincia sarda de la orden mercedaria bien entrado el siglo XVIII, separándola de la aragonesa en Rubino, A.: I mercedari in Sardegna (1336-2000), Roma, Istituto Storico dell'Ordine della Mercede, 2000; GuIA, op. cit., (nota 6), p. 153.

57 Guia Marín, L.: "Pervivencia y ruptura de la tradición jurídico-política de la Corona de Aragón en las ciudades reales del reino de Cerdeña (siglos XV-XVIII)", en Ricordando Alberto Boscolo. Bilanci e Prospettive Storiografiche, Convegno Internazionale, Cagliari, Università degli Studi di Cagliari - Istituto di Storia dell'Europa Mediterranea. CNR, 7-9 noviembre de 2012, en prensa. 
político institucional construido a través de cuatro siglos, sino por que el mundo convulso que rodeaba la isla estaba quemando etapas para que dejase de ser regida por cualquiera de los dos pretendientes a la herencia de Carlos II. Entre esos cambios subliminales que se estaban produciendo en el funcionamiento de las instituciones políticas territoriales y que después tendrán una cierta continuidad en el reino sardo de los Saboya, cabe destacar dos de ellos: la paralización de la vida parlamentaria y con ello la praxis del pactismo desde inicios del setecientos ${ }^{58}$ y la distorsión en el funcionamiento de la Junta del Real Patrimonio, máximo organismo de gestión de las rentas del reino. En cualquier caso no fueron nunca cambios bruscos, tuvieron el carácter de provisionales, o extraordinarios, y siempre se adoptaron en plena compatibilidad con los referentes jurídicos y políticos vigentes ${ }^{59}$.

Por otra parte los cambios realizados bajo la administración de Carlos no se limitaron a la esfera político-institucional, un amplio programa de reformas o actuaciones en la esfera económica fueron propuestas o iniciadas, paralelamente a los acontecimientos bélicos ${ }^{60}$. De alguna manera Carlos también se arrogaba la herencia de Carlos II con estas iniciativas. Los proyectos de reformas del último Habsburgo habían seguido un vacilante y problemático iter en una isla sumida en el marasmo económico en la segunda mitad del seiscientos y en la que sus conexiones comerciales habían sufrido un significativo descenso ${ }^{61}$. La culminación de esos proyectos se plasmó en la pragmática publicada por el último virrey de Carlos II y primero de Felipe V, el duque de San Juan ${ }^{62}$. No resulta ocioso citar tal acontecimiento; la pragmática del Duque de San Juan contenía disposiciones de política económica, que van a mantenerse en las instrucciones que Carlos de Austria redacte para sus virreyes con motivo de su toma de posesión ${ }^{63}$; lo más importante sin embargo, es que tales disposiciones fueron publicadas de nuevo durante los primeros años del gobierno de los Saboya y décadas más tarde en edición bilingüe (castellano-italiano) en el contexto de las reformas de

58 Guia Marín, L.: "Un regne sense Corts. Sardegna en la cruïlla dels canvis dinástics de la Guerra de Successió", Afers, 59, (2008), pp. 67-90. Trabajo publicado con el título: "Un regno senza parlamenti al crocevia della guerra di successione spagnola", en MANCONI, F. (coord.): Il regno di Sardegna in età moderna. Saggi diversi, Cagliari, CUEC, 2010, pp. 99-131.

59 DöBerl, op. cit., (nota 27, 2007); Guia Marín, L.: "Pio Ravizza y la superintendencia de la Caja Militar del Reyno de Cerdeña. Cenit y ocaso de una reforma de Carlos de Austria (1715-1717)", en Mele, G. (coord.): Tra Italia e Spagna. Studi e Ricerche in onore di Francesco Manconi, Cagliari, CUEC, 2012, pp. 77-102.

60 Murgia, op. cit., (nota 30).

61 Manconi, F.: "Cerdeña a finales del siglo XVII-principio XVIII: una larga crisis de casi medio siglo", Estudis. Revista de Historia Moderna, 33, (2007), pp. 27-44.

62 Pregón General.....Sobre todas las materias pertenecientes a la buena administración de Iusticia, fácil, y más breve despacho de las causas, así civiles como criminales; aumento de la Agricoltura; prohibición de armas; privilegios exempciones y obligaciones de los soldados, y Labradores....(ASC, AAR, vol. C5, Pregoni 1456-1710, pp. 395r-427v, 23-VIII-1700, ejemplar impreso en 1726). Sus disposiciones habían sido elaboradas, en gran parte, por los virreyes de Carlos II. En este sentido hay que citar, como mínimo, las disposiciones acordadas durante los virreinatos del conde de Fuensalida, entre 1682-83, del duque de Monteleón, entre 1687-1690, y del conde de Altamira, entre 1690-1696.

63 Guia Marín, L.: "Les instruccions de Carles d'Àustria als virreis de Sardenya (1708-1717): la continuïtat d'una tradició hispànica", en Franch Benavent, R., Benítez Sáchez-Blanco, R. (eds.): Estudios de Historia Moderna en Homenaje a la profesora Emilia Salvador Esteban, vol. 1, Valencia, Departament d'Història Moderna de la Universitat de Valencia, 2008, pp. 269-296. 
finales del siglo XVIII. La reimpresión de esta pragmática en 1780, en edición bilingüe, denota su importancia. A Mattone lo subraya:

...nel 1700 viene promulgato dal viceré, duca di San Giovanni, il Pregón general sobre todas las materias pertenecientes a la buena administración de justicia: suddiviso in quattro sezioni (criminale; civile; milizie; agricoltura) ed in 194 capitoli, il pregone è una vera e propria ricompilazione di tutta la normativa della seconda metà del Seicento. Ristampato nel 1780 in edizione bilingüe, spagnola e italiana, rimase diritto vigente sino al $1827^{64}$.

Volvamos a Carlos de Austria y sus reformas, algunas de ellas demonizadas por una propaganda posterior que le achacó el origen de los males de Cerdeña. Sin duda la economía de guerra obligó a compensar a los fieles, con honores, títulos y dinero, a costa de los recursos de la isla que además se vieron esquilmados para financiar el conflicto. Las disposiciones de Carlos no se apartaban en este sentido de lo que había hecho Felipe $\mathrm{V}$ durante los primeros años de la guerra y volvería a hacerlo en el breve periodo de la invasión de 1717-20. Difícil es determinar si sus disposiciones respondieron a un proyecto de largo alcance o por el contrario se movieron por la coyuntura. La creación de la Superintendencia de la Caja Militar, que podría haber trastocado la estructura de gobierno y gestión del Real Patrimonio, se frustró definitivamente con la invasión borbónica ${ }^{65}$. Sin embargo otras disposiciones de carácter fiscal tuvieron una mayor fortuna y fueron asumidas, por sus indudables beneficios, por los monarcas de la casa de Saboya. Entre ellas destaca la implantación del estanco del tabaco, para lo que hubo que vencer enormes dificultades, planteadas sobre todo por la ciudad de Sassari ${ }^{66}$.

Con todo lo dicho nada parecía indicar que Cerdeña no estuviese plenamente integrada en el contexto político-institucional creado por Carlos VI para administrar los territorios hispánicos conservados y que las medidas de gobierno, que fue tomando durante casi una década, tuviesen de alguna manera un carácter de provisionalidad a la espera de abandonar la isla. Todo lo contrario; tal y como he indicado más arriba, la vinculación de Cerdeña con su monarca parecía plenamente consolidada y a prueba de cualquier intento de separación ${ }^{67}$. Sin embargo, con altos y bajos, la consideración

64 Mattone, A.: "Istituzioni e riforme nella Sardegna del Settecento", en Dal trono all'albero della libertà: trasformazioni e continuità istituzionali nei territori del Regno di Sardegna dall'antico regime all'età rivoluzionaria. Atti del Convegno, Torino 11-13 settembre 1989, Roma, Ministero per i beni culturali e ambientali, 1991, pp. 325-419, cita en nota 35, p. 337.

65 GuIA, op. cit., (nota 56).

66 DöBerl, op. cit., (nota 27, 2007). Sobre este asunto es numerosa la documentación conservada en el fondo Consiglio di Spagna del Archivio di Stato di Napoli.

67 Interesa poner de manifiesto, como ejemplo del que parecía un vínculo indisoluble, el decreto de Carles VI por el cual concedía el título de "Grande de España" a los Estamentos Sardos en 1.716. La concesión tenía un gran valor simbólico. No era solo un simple privilegio sino que el honor iba destinado a la máxima representación política de un reino, al que se le consideraba así parte inseparable de la Corona. Una Corona, la de España, que en buena parte era más virtual que efectiva per la limitación de los territorios que conservaba aquel que se consideraba aún su titular. Sobre la cuestión véase: Putzulu, E.: "La Grandesa de España agli Stamenti Sardi", Cagliari Económica, no 9, Cagliari 1954, pp. 1-8. En los archivos locales hay copia de esta concesión (Archivio Arcivescobile e Capitolare di Cagliari (AACC), seg. 166, Carte reali..., $n^{\circ} 170$, pp. 283r-283v, 18-IV-1716. 
de que Cerdeña podía ser cedida o intercambiada, no había dejado de estar presente en las cancillerías europeas, aunque la documentación local no diese noticias sobre ello. Posiblemente era una idea recurrente que, desde el siglo XVI, no había dejado de gravitar sobre la isla; recordemos como el propio Felipe II salió al paso de tal posibilidad $^{68}$. Según cita de Antonello Mattone ${ }^{69}$, apenas iniciado el conflicto sucesorio, el reino sardo fue ofrecido, en febrero de 1703, a los Saboya por parte del emperador en la perspectiva de una alianza entre el Piamonte y Austria. La propuesta quedó en nada pero resultó a la postre premonitoria del destino final de la isla. Siguiendo al mismo autor, en la segunda mitad del siglo XVII, Francia había mostrado su interés por la posición estratégica de la isla desde el punto de vista comercial pero no se llegaron a plantear propuestas de carácter territorial.

La caja de Pandora se reabrió con las negociaciones de Geertruidenberg en 1710. Previamente en el seno del bando borbónico, y a iniciativa de Luis XIV, se había contemplado la posibilidad de ceder la isla de Cerdeña al príncipe elector de Baviera para resarcirle de sus pérdidas territoriales durante la guerra ${ }^{70}$. Sin embargo el congreso acabaría por considerar, a pesar del apoyo de Luis XIV, que esa idea de la cesión no era practicable de momento. Paralelamente, el curso de los acontecimientos mantuvo el caso sardo como un tema candente, no tanto por que se hubiese tratado directamente del mismo, sino porque por un lado se hizo patente la contradicción entre los intereses piamonteses en Terraferma que chocaban con el dominio del emperador en Milán y por otro se evidenció la estrategia de Inglaterra que, para neutralizar la omnipresencia "austriaca" en el Mediterráneo, apoyará la presencia piamontesa en Sicilia. Esa presencia obligaba a redefinir los referentes de poder en la zona y a tratar de rechazo del futuro de Cerdeña. La presencia en el Mediterráneo acabó por agradar al duque de Saboya que aspiraría a reinar, como alternativa a expandirse de manera inmediata por el norte de Italia, en un gran reino constituido por Nápoles y Sicilia, sin excluir su expansión futura por el Milanesado.

Cuando se inician en Utrecht las negociaciones de paz en enero de 1712, Vittorio Amedeo y sus ministros empezarán a comprender que la adquisición de Milán era inalcanzable y que la opción mediterránea se consolidaba como mucho más realista. No lo pensaban ellos solos, Inglaterra ${ }^{71}$ estaba decidida a que el duque de Saboya se convirtiese en rey de Sicilia, mientras que Cerdeña, siempre considerada un premio de consolación, se reservaba al príncipe elector de Baviera, Max Emanuel de Wittelsbach, que años antes, en 1702, había aspirado a convertirse en rey de Nápoles y Sicilia como uno de los herederos de Carlos II ${ }^{72}$.

\footnotetext{
68 Véase: nota 14.

69 Mattone, op. cit., (nota 31), p. 12.

70 ENDERs, op. cit., (nota 32), pp. 18-19.

71 Bacallar destaca el protagonismo de Inglaterra en estas propuestas: "Los ingleses, que en este tiempo dieron la ley a la Europa, estaban firmes, no sólo en que se había de restituir sus Estados y dignidades al duque de Baviera, pero que por los daños padecidos se le había de dar el reino de Cerdeña, si quería el Emperador quedarse con la Flandes". Véase: BACAllar, op. cit., (nota 37), pp. 230.

72 ENDERS, op. cit., (nota 32), pp. 19-20.
} 
A lo largo de $1712^{73}$, asumida plenamente la opción sarda por Max Emanuel, sus instancias para hacer efectivo el nombramiento como futuro rey se volverían cada vez más insistentes. El camino no fue fácil y tuvo que hacer frente a numerosas contrariedades. Entre ellas la oposición del emperador que prefería como futuro rey de Cerdeña al elector palatino, el príncipe Johann Wilhelm, uno de sus aliados. Sin embargo este último, que debía ceder a cambio el Alto Palatinado, se mostró explícitamente contrario al proyecto en febrero de 1713. Finalmente, en marzo de ese mismo año, los esfuerzos del elector de Baviera parecía que iban a tener la esperada recompensa; los plenipotenciarios del emperador, los de Francia y los de Inglaterra, acordaron la cesión de la isla al elector a cambio de los Países Bajos españoles. Incluso tal eventualidad se reflejó en el Tratado firmado entre Francia y Holanda el 11 de abril de 1713. Acuerdos complementarios perfilaron todos los detalles del protocolo a seguir para hacer efectivo el intercambio, que comportaba también la restitución al elector de sus territorios bávaros. Para remachar el clavo, una nueva conferencia de plenipotenciarios de Austria, Francia e Inglaterra confirmó el 15 de mayo la cesión de Cerdeña con el título de rey al elector de Baviera, que llegó a celebrar su designación como si fuese ya efectiva ${ }^{74}$.

Sin embargo la paz se resistía a prevalecer en todos los frentes y territorios involucrados en la Guerra de sucesión y las negociaciones de Utrecht estaban destinadas a no ser las únicas ni las últimas que abriesen el camino para conseguirla. Finalmente el emperador no firmó el tratado de paz, quedando en suspenso la promesa hecha al elector bávaro. Bacallar diría al respecto:

...y así en Utrech no se resolvía sobre Flandes, como cosa que quedaría a la Casa de Austria; pero ésta repugnaba se diese la Cerdeña al duque de Baviera, como querían los ingleses y franceses; y como dependía del Emperador reintegrar en sus Estados al duque, se dejó esta circunstancia en abierto, porque los alemanes querían tratar sólo con la Francia de esta dependencia ${ }^{75}$.

Así pues las propuestas barajadas en Utrecht para Cerdeña acabarán por no tener ninguna efectividad ante la oposición sobrevenida del emperador, que a principios de otoño resucitó la candidatura del elector palatino a la corona del reino sardo; esta vez con la aquiescencia del mismo; posiblemente se trataba de una maniobra imperial para conseguir nuevos réditos territoriales a costa del elector de Baviera. Carlos VI había aumentado el nivel de exigencias: el elector tendría que renunciar a Baviera si deseaba Cerdeña; como mucho podría mantener los Países Bajos, aun recibiendo el reino sardo, pero el tema de Baviera parecía innegociable para el emperador ${ }^{76}$. Paralelamente Max Emanuel perdía rápidamente el apoyo de Luis XIV, el más fuerte que había tenido para convertirse en rey de Cerdeña. Desde octubre de 1713 se iniciaba

\footnotetext{
73 También Francia apoyó decididamente la opción de ceder Cerdeña al elector de Baviera. Véase Castellví, op. cit., (nota 36), vol. 3, p. 404.

74 Enders, op. cit., (nota 32), pp. 22-23.

75 Bacallar, op. cit., (nota 37), pp. 236-237. También Castellví da noticia de las últimas dificultades para llegar a un acuerdo que satisficiese al emperador, CASTELlví, op. cit., (nota 36), vol. 3, pp. 516-517.

76 S. Enders destaca como simultáneamente el elector empezó a encontrar oposición en la propia Baviera al proyecto "sardo-bavarés", ENDERs, op. cit., (nota 32), p. 27.
} 
una nueva ronda de negociaciones entre Francia y Austria que darían lugar al tratado de Rastadt y acabarían con el espejismo del reino sardo-bavarés.

Por lo que respecta a la suerte seguida por Sicilia, el Tratado de Utrecht sancionaba, como hemos dicho, la presencia piamontesa en el Mediterráneo erigiéndose como una barrera entre las posesiones del emperador y las de Felipe V, tal y como deseaba Inglaterra. Entre abril y julio de 1713, Vittorio Amedeo había acordado la paz con Francia y con Felipe V, firmando el tratado de paz con este último el 13 de julio. El Saboya recibía Sicilia pero tuvo que aceptar la renuncia de sus expectativas iniciales sobre el norte de Italia e incluso sobre Nápoles. En cualquier caso Sicilia iba a ser considerada por el duque como una posible pieza de intercambio en un futuro próximo con territorios de Terraferma ${ }^{77}$. Finalmente en diciembre de ese mismo año 1713 Vittorio Amedeo era coronado en Palermo.

Antonello Mattone destaca la trascendencia para el futuro de Cerdeña de las condiciones de la cesión de Sicilia que contemplaban una serie de cláusulas que aseguraban la conservación de las leyes y privilegios del reino. Cuando Sicilia fuese intercambiada, años más tarde, por Cerdeña, esas cláusulas serán tácitamente aplicadas al reino sardo lo que permitirá que mantenga su contexto jurídico y su estructura político-institucional bajo los Saboya ${ }^{78}$. En el último cuarto de siglo XVIII, cuando estos inicien un amplio paquete de reformas, que vulneraban esas cláusulas, se producirá una fuerte reacción de los estamentos, inicialmente con un carácter reaccionario y liderados por la nobleza ${ }^{79}$ pero años más tarde la reivindicación del "derecho patrio", vulnerado por los Saboya, calaría en los ambientes revolucionarios de la sociedad sarda vísperas de la crisis del Antiguo Régimen ${ }^{80}$. De alguna manera, aunque Cerdeña no fuese protagonista directa de los acuerdos finales de Utrecht, algunas de las decisiones tomadas en este congreso van a marcar su historia inmediata y futura.

Meses después del tratado de Utrecht, el tratado de Rastadt, estipulado el 6 de marzo de 1714 entre Francia y el emperador, reconocía a éste el dominio sobre los Países Bajos españoles, sobre el reino de Nápoles, sobre el ducado de Milán, sobre el reino de Cerdeña y sobre los presidios de la Toscana. Nada quedaba de las aspiraciones de Max Emanuel de Baviera para convertirse en rey de Cerdeña; un mes antes le había sido restituida Baviera, a la que no regresaría hasta 1715. En el entretanto se mantuvo en Madrid, esperando un giro en los acontecimientos. Evidentemente la frustración de Max Emanuel y de todos aquellos que le apoyaban se trasformó, durante 1714, en

77 Mattone, op. cit., (nota 31), p. 18. Una actitud premonitoria de la política seguida por el mismo monarca, a partir de 1720, con respecto a Cerdeña: considerarla como una adquisición provisional; actitud que durará, en el caso sardo, al menos hasta mediados del siglo XVIII con la paz de Aquisgrán. A partir de esa fecha se puede decir que los Saboya asumieron la posesión de la isla con todas sus consecuencias.

78 MatTone, op. cit., (nota 31), pp. 19-21.

79 Guia Marín, L.: "In Memoriam de la Corona d'Aragó. Reformes i reacció a Sardenya en la segona meitat del segle XVIII", Estudis. Revista de Historia Moderna, 37, (2011), pp. 305-323.

80 Guia Marín, L.: "El derecho "patrio" en el reino de Cerdeña y la dinastía de los Saboya", en VIII Jornadas Internacionales de Historia de las Monarquias Ibéricas. el gobierno de la virtud. política, ciencia y moralen las monarquías ibéricas y Europa (ss. XVI-XVIII), Departament d'Història Moderna de la Universitat de València - Red Columnaria, Valencia, 19 a 21 de noviembre de 2012, en prensa. 
un redoblar de esfuerzos para conseguir, aunque fuese por la fuerza, la entrega de la isla y la asunción del título de rey ${ }^{81}$.

La presencia del emperador en Italia, justificada inicialmente, durante el conflicto, por erigirse como heredero de Carlos II, en definitiva por ser rey durante un tiempo de la Monarquía Hispánica, adquiría otra dimensión: ahora era el emperador de Austria el que pasaba a poseer, con el reconocimiento internacional, parte de esos territorios que habían conformado la Monarquía Hispánica ${ }^{82}$, mientras que al otro lado del mar había sido reconocido, como rey de España, Felipe V. Se abría un nuevo equilibrio, a gusto de Inglaterra, que impedía la preponderancia de alguna potencia en la Europa Occidental y especialmente en el Mediterráneo próximo, donde los súbditos británicos estaban ampliando su presencia comercial.

Desde la perspectiva de Cerdeña llegar ahí sin cambios no había estado fácil; para esas fechas, a finales de 1713 y principios de 1714, se habían tenido que superar algunos de los momentos más críticos en los que se había discutido mucho en las cancillerías europeas sobre el futuro de la isla. Justo a continuación apareció otro peligro: la amenaza de una invasión militar promovida por el elector de Baviera, que hubiese podido complicar la continuidad de la vinculación de Cerdeña a Carlos de Austria, planeó durante toda la primavera de 1714. Una invasión que también preveía la abolición de todo el contexto jurídico y político-institucional del reino en beneficio de las aspiraciones absolutistas de Max Emanuel ${ }^{83}$.

Como hemos dicho, no hay demasiados rastros de las discusiones sobre el futuro de Cerdeña en la documentación local ${ }^{84}$, tampoco de manera explicita de la proyectada invasión. Evidentemente la posible cesión diplomática de la isla, con o sin la complicidad del emperador, se mantuvo en secreto para evitar reacciones locales en contra. La defensa del reino, por el contrario, se instrumentalizó coyunturalmente para recabar y reforzar las fidelidades al emperador. De hecho el telón de fondo para la constitución de la Superintendencia de la Caja Militar en Cerdeña, a principios de 1714, tuvo como bandera de enganche la necesidad de aprestar el reino para su defensa ${ }^{85}$; la invasión no se produjo finalmente durante esa campaña. Meses después se plantearon otros motivos de preocupación a punto de iniciarse la campaña siguiente de 1715 ante una nueva posible invasión, en este caso de Felipe V. Las referencias en la documentación son constantes. Se pensaba que el duque de Anjou aya conzebido alguna idea contra el reyno de Cerdeña; y que hallándose oy desembarazado de la

81 ENDERS, op. cit., (nota 32), pp. 28-29 y 43-44.

82 Sobre el marco político después de Utrecht en relación a las posesiones imperiales en Italia véase: LeÓn SAnz, V.: "Una imagen austracista de Europa después de la Paz de Utrecht", en GuimerÀ, A., Peralta, V. (coords): El equilibrio de los imperios: de Utrecht a Trafalgar, Madrid, Fundación Española de Historia Moderna, 2005, pp. 133-154; Molas Ribalta, P.: “¿Qué fue de Italia y Flandes?”, en Álvarez-Ossorio, op. cit., (nota 15), pp. 693-715; GuAsti, N., Russo, S. (coords.): Il viceregno austriaco (1707-1734). Tra capitale e province, Roma, Carocci, 2010.

83 Enders, op. cit., (nota 32), pp. 171 y ss.

84 Solo en el marco de la guerra de propaganda contra el contrario, hemos podido localizar alguna referencia sobre la hipotética cesión de la isla en fechas anteriores. En un bando impreso en 1710 se acusa a los franceses de pretender conquistar Cerdeña, para después permutarla por plazas perdidas en el norte de Francia. (Archivio Comunale di Cagliari (ACC), Archivio Storico (AS), vol. 36, Carte Vicereali 1364-1841).

85 DöBerl, op. cit., (nota 27, 2007); GuIA, op. cit., (nota 56). 
guerra de Catalunya y con navíos y galeras suficientes piense con mayor fervor en practicarla.

Con estas palabras el emperador alertaba, en enero de 1715, al virrey conde de la Atalaya, de esta circunstancia al tiempo que comunicaba al gobernador de Milán y al virrey de Nápoles que se aprestasen para auxiliar a Cerdeña en caso de que se produjese alguna invasión ${ }^{86}$. De hecho, como destaca Mario Döberl, se había producido un cambio en la posición estratégica de Cerdeña, tras la caída de Barcelona en septiembre de 1714:

La Sardegna, che fino a quel momento aveva avuto un'importante posizione strategica tra l'Italia e la parte della Spagna controllata da Carlo VI, era divenuta ormai un avamposto solitario degli Asburgo in mezzo alla vasta area del mediterraneo occidentale. L'imperatore non disponeva neanche di una flotta idonea per difendere l'isola lontana, che per lui ora era solo di utilità limitata contro eventuali aggressori ${ }^{87}$.

A pesar de su triunfo en la península ibérica, Felipe $\mathrm{V}$ todavía tenía demasiadas preocupaciones como para embarcarse en una inmediata invasión de Cerdeña, de tal manera que las noticias alarmantes del mes de enero dieron paso a una realidad en la que la presión bélica parecía aflojarse. Posiblemente la firma, en septiembre de 1714, del tratado de Baden, uno más de los que iban poniendo fin a la Guerra de Sucesión española, había aportado un nuevo alivio. De hecho tras la comunicación al virrey por parte del emperador, en febrero de 1715, del resultado de ese tratado ${ }^{88}$, la ciudad de Sassari decidió organizar fiestas por el final de la guerra a mediados de abril de $1715^{89}$. Cerdeña parecía entrar en una situación de tranquilidad y siguió en su urna de cristal, estrechando aparentemente cada vez más su vinculación con Carlos de Austria.

Sin embargo, pronto se demostró que el nuevo equilibrio de Utrecht y Rastadt no sería suficiente para asegurar la tranquilidad y la seguridad de la zona. La insatisfacción de unos y otros pondría en cuestión el statu quo territorial y Cerdeña estaba en medio de ese escenario; a pesar de ser un reino pobre estaba destinado a ser pieza fundamental del rompecabezas para retocar el precario equilibrio acordado en 171314; precariedad producida sobre todo por que Carlos VI y Felipe V no habían firmado la paz entre ellos. El irredentismo de Felipe $\mathrm{V}$ no dejaba de considerar los territorios italianos, incluida Cerdeña, como un espacio sobre los que proyectar de nuevo la influencia española, mientras tanto la muerte de la reina Anna, en agosto de 1714, y la llegada al trono de Jorge I implicó un mayor acercamiento de éste, como elector de Hannover, al emperador.

Al paso de dos años, la idea de entregar el reino de Sicilia a Carlos VI, arrebatándoselo a Vittorio Amedeo, se había abierto paso poco a poco en la cancillería inglesa.

${ }^{86}$ ASN, CS, vol. 19, pp. 73r-73v, 3 de enero de 1715; pp. 94v-95v, 12 de enero de 1715 y pp. 93r-94r, 16 de enero de 1715 , respectivamente.

87 DöBERL, op. cit., (nota 27, 2007), pp. 226-227.

88 Putzulu, E.: Carte reali aragonesi e spagnole dell'Archivio Comunale di Cagliari (1368-1719), Padova, CEDAM, 1959, p. 153).

89 DöBERL, op. cit., (nota 27, 2007), p. 243 
Ello ponía encima de la mesa una reconsideración de los acuerdos de Utrecht, y en ese proceso el futuro de Cerdeña iba a depender de la solución que se acordase para Sicilia ya que se convertía en la única posibilidad real de compensar a los Saboya de la pérdida de su nuevo reino, al descartarse además cualquier concesión a Piamonte en los territorios imperiales del norte de Italia. A pesar de las gestiones y resistencias del monarca piamontés la solución parecía cantada; con ella se contentaría al emperador y se podría hacer frente a un posible intento de Felipe $\mathrm{V}$ de reinstaurar el dominio español en Italia.

De las ideas se pasó pronto a los acuerdos, públicos o secretos, que contemplaban ese intercambio, y a las presiones sobre Vittorio Amedeo. La primera ocasión en que ello ocurre, citada por Antonello Mattone, se dio en 1716 y a iniciativa de la diplomacia inglesa. El rey de Sicilia, apelando a los acuerdos de Utrecht, pudo resistirse de momento a lo que no dejaba de ser una seria amenaza, sin embargo nuevos tratados bilaterales entre otras potencias, como los habidos entre Jorge I y Carlos VI, o entre Francia e Inglaterra, empezaron a incorporar cláusulas que preveían la cesión futura de Sicilia ${ }^{90}$. La situación dio una nueva vuelta de tuerca cuando el equilibrio conseguido en Utrecht y Rastatt en el espacio mediterráneo se rompió en pedazos por el irredentismo de Felipe V y de su ministro Alberoni. Tras la invasión de Cerdeña y Sicilia en 1717-18, no solo la resistencia de Vittorio Amedeo al intercambio perdía toda su fuerza, al haber sido incapaz de resistir y conservar su reino, sino que, por el capricho de la estrategia del ataque borbónico, la resolución del conflicto planteado en las dos islas debía ser abordado coordinadamente.

La Triple Alianza, convertida rápidamente en Cuádruple, reaccionó de inmediato frente a la acción de Felipe $\mathrm{V}$ y decidió no solo recuperar, sino recomponer e imponer el equilibrio alcanzado años antes en Utrecht y Rastatt. Esta vez la sede de los acuerdos fue la capital inglesa. A partir del tratado de Londres de 2 de agosto de 1718 Felipe V fue obligado a abandonar sucesivamente las islas y, por servidumbres de la diplomacia internacional y los protocolos jurídico-políticos, debió devolver al emperador Cerdeña. Era éste un regreso formal a la situación inmediatamente anterior a la crisis pero en cumplimiento del Tratado Vittorio Amedeo debería ceder de manera inmediata Sicilia al emperador, que dominaría así el sur de Italia, y aceptar Cerdeña como premio de consolación ${ }^{91}$. Por fin la decisión sobre Cerdeña, largamente gestada en las negociaciones de la diplomacia europea, se ponía en práctica. Con ello Cerdeña, último reducto jurídico, político e institucional de la extinta Corona de Aragón, dejaba de estar vinculada a uno de los monarcas que aspiraron y lucharon por la herencia de Carlos II; de hecho para la isla, los acontecimientos desencadenados a partir de 1717, y que cerraron su ciclo en 1720, fueron el último episodio de su particular Guerra de Sucesión ${ }^{92}$.

90 Mattone, op. cit., (nota, 31), p. 22.

91 A. Mattone destaca que el tratado de Londres, continuación natural de los acuerdos de Utrecht, validaban un cambio profundo en las relaciones internacionales, poniendo fin a la hegemonía que secularmente se había ejercido sobre Italia desde la península ibérica, Ibidem, p. 25.

92 Como destacó Miguel Ángel Alonso Aguilera "parece como si, durante la conquista de la isla y el dominio borbónico, se hubiese prolongado dicha conflagración (la guerra de Sucesión) en evidente anacronismo cronológico, que no ideológico ni geográfico”, ALonso, op. cit., (nota 22), p. 121 
El reino sardo pasaba, en 1720, a depender de un pequeño monarca, que había sido instituido como rey de Sicilia a partir de Utrecht y que ahora llegaba a Cerdeña con corona pero sin reino. Solo este detalle compensó de momento a Vittorio Amedeo; la posesión de Cerdeña le permitió mantener el título regio y la esperanza de engrandecer sus territorios de Terraferma a costa de una ulterior cesión de la isla. Como he indicado previamente esta actitud de los Saboya se perpetuaría durante gran parte de XVIII, contribuyendo a mantener a Cerdeña en un marasmo económico, social y político. Sin duda el Saboya era un príncipe completamente extraño a las tradiciones históricas y civiles del país que debía gobernar. Un país del que debía respetar, por las cláusulas de cesión, los intereses consolidados de los estamentos privilegiados, las instituciones políticas y las costumbres jurídicas. Para que así fuese, las potencias promotoras del tratado y los anteriores gobernantes de la isla se erigieron como efímeros garantes.

A la postre la vinculación de Cerdeña a los monarcas piamonteses implicaría, no solo su integración definitiva en el espacio italiano, que se había acelerado cuando se estrecharon sus vínculos con Nápoles y Milán de la mano de Carlos de Austria, sino el inicio de un lento pero sistemático proceso de italianización ${ }^{93}$ que marcará el destino posterior de la isla y su fusión con el Piamonte en el siglo XIX.

\footnotetext{
93 Sobre el papel de la Iglesia en el proceso desde el punto de vista lingüístico, véase TuRTAS, R.: "Pastorale vescovile e suo strumento linguistico. I vescovi sardi e la parlata locale durante la dominazione spagnola e sabauda", Rivista di Storia della Chiesa in Italia, XLII-I (1988), Roma, pp. 1-23.
} 